\title{
Family planning, pregnancy and birth in women with lung conditions: a worldwide survey
}

\author{
Clare Williams ${ }^{1}$, Barbara Johnson ${ }^{1}$, Peter G. Middleton $\mathbb{B}^{2}$, Vibeke Backer ${ }^{3}$, Peter G. Gibson ${ }^{4}$, \\ Gill Hollis ${ }^{5}$ and Courtney Coleman ${ }^{1}$
}

${ }^{1}$ European Lung Foundation, Sheffield, UK. ${ }^{2}$ CF Research Group, Ludwig Engel Centre for Respiratory Research, Westmead Institute for Medical Research, University of Sydney, Sydney, Australia. ${ }^{3}$ Department of ENT and CFAS, Rigshospitalet, Copenhagen University, Copenhagen, Denmark. ${ }^{4}$ Centre for Asthma and Respiratory Diseases, Faculty of Health and Medicine, University of Newcastle, Newcastle, Australia. ${ }^{5}$ LAM Action, Newark, UK.

Corresponding author: Clare Williams (clare.williams@europeanlung.org)

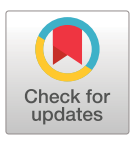

Copyright @The authors 2021

This version is distributed under the terms of the Creative Commons Attribution NonCommercial Licence 4.0. For commercial reproduction rights and permissions contact permissions@ersnet.org

This article has supplementary material available from openres.ersjournals.com

Received: 27 May 2021

Accepted: 19 Sept 2021

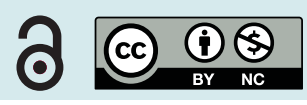

Shareable abstract (@ERSpublications)

This survey found that having a lung condition can play a significant role in women's decisions around family planning, pregnancy and birth. Women wanted more specialist support and better information before, during and after pregnancy. https://bit.ly/3CSpHt9

Cite this article as: Williams C, Johnson B, Middleton PG, et al. Family planning, pregnancy and birth in women with lung conditions: a worldwide survey. ERJ Open Res 2021; 7: 00357-2021 [DOI: 10.1183/ 23120541.00357-2021].

\section{Abstract}

Lung diseases can complicate pregnancy, but little is known about the experiences of pregnancy among women living with such diseases. This survey aimed to understand the experiences of women with a lung condition before and during pregnancy, in childbirth and post-partum.

The survey was translated into nine languages and hosted online between March and May 2018. This paper reports on 327 women who had asthma, cystic fibrosis (CF), lymphangioleiomyomatosis (LAM) and sarcoidosis as a sole or primary lung condition.

Women with CF and LAM were most likely to report that their condition influenced their decision to have children. Those with CF and LAM who did become pregnant reported greater satisfaction with their healthcare during pregnancy and gave more consideration to factors such as location and type of birth; they were also more concerned about the impact of the pregnancy on their health than women with other diseases. Women with sarcoidosis reported receiving conflicting advice as to both the impact of their condition on pregnancy and how becoming pregnant might impact their health. Women with asthma reported not always being able to access the information they needed from healthcare professionals.

The results suggest that healthcare providers should be having dialogues with affected women early on, from before conception, throughout the pregnancy and after giving birth, and training should be provided to healthcare staff to equip them with the information they need to do this.

\section{Introduction}

Lung diseases can impact on pregnancy and family planning decisions, but little is known about the experiences of women living with such diseases. Asthma is one of the most common health conditions affecting women of reproductive age, and studies have suggested that women with asthma take longer to conceive and are more likely to require fertility treatment [1]. Asthma exacerbations during pregnancy have been linked to negative maternal and fetal outcomes [2]. Cystic fibrosis (CF) is usually diagnosed in childhood and can influence female fertility [3]. Many women with CF can conceive without difficulty, although genetic testing is recommended for the woman's partner [3, 4]. Premature delivery is higher in women with CF, and those with reduced lung function are more likely to need a caesarean delivery [4].

Lymphangioleiomyomatosis (LAM) has no reported effect on fertility. However, pregnancy in women with LAM has been associated with increased complications, premature birth and worsening lung function, which can remain post-partum [5, 6]. Sarcoidosis does not affect fertility but some medications can have an adverse impact [7]. While there is usually no impact on pregnancy [7], and some women find their 
sarcoidosis improves [8], some studies have shown an increased risk of negative outcomes including pre-eclampsia, pulmonary embolism and premature delivery [9]. Table 1 describes the four lung diseases included in this study.

Most psychological studies of pregnancy have excluded women with chronic illness to avoid confounding factors, resulting in a lack of information on women's experiences and perspectives [26]. Previous research exploring the experiences of family planning and pregnancy in women with lung disease focused on single diseases, most frequently $\mathrm{CF}$, and used a range of qualitative and quantitative methods. Women with chronic lung diseases reported a lack of clear information and support from healthcare professionals, uncertainty about the safety of medications during pregnancy and the impact of their illness on the baby, and concerns about balancing their illness with parenthood [4, 27, 28, 29, 30, 31, 32, 33]. Women with CF and LAM had concerns about dying early and many chose not to or were advised by professionals not to become pregnant due to the perceived impact on their health $[4,27,29,31,32,34]$. There has been little research into the experiences of women with sarcoidosis.

This paper provides more detailed qualitative and quantitative analysis of the perspectives of women with asthma, CF, LAM and sarcoidosis.

\section{Methods}

Questionnaire topics were identified by the European Lung Foundation (ELF) following a review of previous research and in consideration of the aims of the ERS/TSANZ (Thoracic Society of Australia and New Zealand) Task Force [3]. Topics were developed into an online questionnaire in collaboration with patient representatives and members of the Task Force. The questionnaire was hosted on SurveyMonkey for 1.5 months (between March and May 2018). The ELF, ERS and TSANZ patient and organisational networks were used to promote the survey via their websites, social media and email. Professionals involved in the Task Force also used their networks and contacts with local patient organisations to promote the survey.

The survey was open to people with a lung condition who had considered having children, had been pregnant in the past or were currently pregnant, or who had decided not to become pregnant because of their lung condition.

\begin{tabular}{|c|c|c|c|c|}
\hline Condition & Prevalence & Age of diagnosis & Prognosis & $\begin{array}{l}\text { Effect on female fertility/ } \\
\text { pregnancy }\end{array}$ \\
\hline Asthma & $\begin{array}{l}\text { Common: } 339 \text { million } \\
\text { worldwide [10] } \\
\text { Childhood asthma more } \\
\text { common in males; } \\
\text { adult asthma more } \\
\text { common in females [11] }\end{array}$ & $\begin{array}{c}\text { Usually diagnosed in } \\
\text { childhood but can affect } \\
\text { any age [12] }\end{array}$ & $\begin{array}{c}\text { Estimated mortality rate of } 0.19 \\
\text { deaths per } 100000 \text {; higher in } \\
\text { low to middle income countries } \\
{[13]}\end{array}$ & $\begin{array}{l}\text { Some studies suggest a link } \\
\text { between asthma and infertility. } \\
\text { In pregnancy, asthma may } \\
\text { improve or worsen - worsening } \\
\text { is more common in severe } \\
\text { asthmatics [3] }\end{array}$ \\
\hline Cystic fibrosis & $\begin{array}{l}\text { Rare: } 1 \text { in } 2500-3000 \\
\text { live births - around } 85 \\
000 \text { worldwide [14]. } \\
\text { Most common in } \\
\text { Caucasians, least } \\
\text { common in Asians [15] }\end{array}$ & $\begin{array}{l}75 \% \text { diagnosed by the } \\
\text { age of } 2 \text { in Western } \\
\text { societies [16]. Many } \\
\text { countries have newborn } \\
\text { screening }\end{array}$ & $\begin{array}{l}\text { Average life expectancy } 35- \\
40 \text { years in USA and UK; lower in } \\
\text { developing countries [17] }\end{array}$ & $\begin{array}{l}\text { Some impact on fertility; } \\
\text { pregnancy carries risks of health } \\
\text { complications for mother and } \\
\text { child and increased treatment } \\
\text { burden [3] }\end{array}$ \\
\hline LAM & $\begin{array}{l}\text { Very rare: estimates } \\
\text { between } 3 \text { and } 5 \text { cases } \\
\text { per million [18]. Almost } \\
\text { exclusively affects } \\
\text { women [19] }\end{array}$ & $\begin{array}{l}\text { Average age of diagnosis } \\
\text { is approximately } 35 \text { [20] }\end{array}$ & $\begin{array}{c}\text { Estimated median } \\
\text { transplant-free survival time for } \\
\text { LAM patients in the US is } \\
29 \text { years from symptom onset } \\
\text { and } 23 \text { years from diagnosis [21] }\end{array}$ & $\begin{array}{l}\text { No reported impact on fertility; } \\
\text { LAM may be accelerated by } \\
\text { oestrogen so may develop or } \\
\text { worsen in pregnancy and lead to } \\
\text { health complications for the } \\
\text { mother [5] }\end{array}$ \\
\hline Sarcoidosis & $\begin{array}{l}\text { Rare: estimates } \\
\text { between } 20 \text { and } 400 \text { per } \\
\text { million depending on } \\
\text { country [22] }\end{array}$ & $\begin{array}{c}75 \% \text { in UK diagnosed } \\
\text { between ages } 30 \text { and } \\
60 \text { [23]; average age of } \\
\text { diagnosis in USA is } \\
55 \text { [24] }\end{array}$ & $\begin{array}{l}\text { Usually normal; } 60 \% \text { will go into } \\
\text { remission, } 10 \% \text { will develop } \\
\text { serious disease that may } \\
\text { shorten life expectancy [25] }\end{array}$ & Usually no impact [7] \\
\hline
\end{tabular}


The survey was available in nine languages: English, French, German, Greek, Italian, Polish, Portuguese, Russian and Spanish.

Following discussion with the Task Force, specific ethical approval was not sought for this study. In considering patients as study participants, ethics committee approval is not generally required for online questionnaires as the methodology is considered to pose a minimal risk to the participant. The ELF adheres to strict ethical principles in questionnaire design, data collection and analysis. Questions were agreed with patient representatives. Transparency of purpose and inclusion/exclusion criteria were provided at the start of the questionnaire, so prospective participants could raise queries or concerns. A contact name and email address for an ELF staff member were provided in case participants had any concerns or questions. Participation was completely voluntary and recruitment was not targeted to individual patients. Respondents were free to skip questions and leave the questionnaire/project at any time. All responses were anonymous, as respondents were directed to a separate form if they wished to provide a contact email address to receive a copy of the survey results.

\section{Analysis}

Numerical data were summarised and group data compared using nonparametric statistics. To determine whether there were differences in responses between different lung conditions, data were analysed using a chi-squared test. Significance was accepted when $\mathrm{p}<0.05$. Responses to open-ended questions were translated into English and coded for overall themes using reflexive thematic analysis [35, 36]. This is a method for identifying, analysing and reporting patterns (themes) within data whereby the researcher familiarises themselves with the data, codes these data and develops and defines themes. An inductive approach was chosen in which themes are grounded in the data in a "bottom up" way, without trying to fit into a pre-existing coding framework (as for a deductive or "top-down" approach), given the aim of the survey was to understand a wide range of views on a relatively under-researched topic. Coding was completed by BJ and the themes were discussed with CC. Differences in experiences between lung conditions were highlighted and four main themes identified.

\section{Results}

The survey had 577 responses from women with a range of respiratory conditions. For the purposes of this paper, respondents with CF, LAM, asthma or sarcoidosis were included; those respondents who marked that they had both CF and asthma and/or bronchiectasis were included in the CF group. Table 2 shows the respondents who were excluded from the analysis. Table 3 shows the characteristics of included respondents.

\section{Experience of pregnancy with a lung disease}

A total of 226 (69\%) respondents were pregnant at the time of the survey or had had a previous pregnancy. During pregnancy, 62\% of these respondents described the standard of care they received for their lung condition as good or excellent, and $15 \%$ as very poor or poor, with the remainder (23\%) satisfactory. Women with LAM and CF were most likely to rate the care they received as good or excellent and women with asthma and sarcoidosis as poor or very poor $\left(\chi^{2}(1, \mathrm{n}=100)=11.6, \mathrm{p}=<0.001\right)$.

When planning childbirth, 26\% of all respondents said that their lung condition was the biggest factor in where they gave birth, but this varied between conditions. Respondents with LAM and CF were most likely to say their condition was the biggest influence on where they gave birth, and those with asthma and sarcoidosis that it had no influence $\left(\chi^{2}(1, \mathrm{n}=77)=23.1, \mathrm{p}=<0.001\right)$. The extent to which a respondent's lung condition influenced how they gave birth - for example, caesarean section, pain management -

TABLE 2 Excluded respondents

Reason for exclusion

Respondents

Returned an incomplete survey

Had more than one lung condition

Had a lung condition other than CF, LAM, asthma or sarcoidosis

Stated they did not have a lung condition or did not answer what lung condition they had

Developed a lung condition after their last pregnancy

Did not answer if they had ever been pregnant or state when they had been pregnant

CF: cystic fibrosis; LAM: lymphangioleiomyomatosis. 


\begin{tabular}{|c|c|}
\hline \multicolumn{2}{|l|}{ Lung condition } \\
\hline Cystic fibrosis, all & $172(52.60 \%)$ \\
\hline Asthma only & $87(26.61 \%)$ \\
\hline Sarcoidosis only & $43(13.15 \%)$ \\
\hline LAM only & $25(7.65 \%)$ \\
\hline Total & 327 \\
\hline \multicolumn{2}{|l|}{ Country of residence } \\
\hline Spain & $87(26.61 \%)$ \\
\hline UK & $76(23.24 \%)$ \\
\hline Germany & $37(11.31 \%)$ \\
\hline Ireland & $21(6.42 \%)$ \\
\hline Belgium & $16(4.89 \%)$ \\
\hline Denmark & $13(3.98 \%)$ \\
\hline USA & $12(3.67 \%)$ \\
\hline Australia & $11(3.36 \%)$ \\
\hline Greece & $8(2.45 \%)$ \\
\hline Switzerland & $7(2.14 \%)$ \\
\hline Netherlands & $6(1.83 \%)$ \\
\hline Norway & $6(1.83 \%)$ \\
\hline Poland & $5(1.53 \%)$ \\
\hline Other & $16(4.89 \%)$ \\
\hline Not given & $6(1.83 \%)$ \\
\hline Total & 327 \\
\hline \multicolumn{2}{|l|}{ Pregnancy status } \\
\hline Never pregnant & $101(30.89 \%)$ \\
\hline Currently pregnant & $23(7.03 \%)$ \\
\hline Last pregnancy in 2010 or after & $143(43.73 \%)$ \\
\hline Last pregnancy in 2000 s & $42(12.84 \%)$ \\
\hline Last pregnancy before 2000 & $17(5.20 \%)$ \\
\hline Last pregnancy date not given & $1(0.31 \%)$ \\
\hline Total & 327 \\
\hline
\end{tabular}

followed similar patterns. Those with LAM and CF were most likely to say that their lung condition was the biggest influence, and those with sarcoidosis and asthma that it had no influence $\left(\chi^{2}(1, n=76)=13.256\right.$, $\mathrm{p}=<0.001)$.

Prior to becoming pregnant, $48 \%$ of women reported speaking to a primary care professional and $61 \%$ to a respiratory specialist about becoming pregnant with a lung condition: $27 \%$ of women rated the information they received from a primary care professional before pregnancy as poor or very poor; $48 \%$ of women rated the information they received from respiratory professionals as good or excellent before pregnancy and $52 \%$ during; $15 \%$ rated the information as very poor or poor before pregnancy and $17 \%$ during.

After giving birth, 67\% of respondents felt they had not received support and advice about breastfeeding with a lung condition. This varied between conditions, with 38\% of those with CF saying they had received this support, compared to none of the respondents with LAM. When asked whether they had received support and advice about how breastfeeding can increase or reduce the chances of their baby developing a lung condition in the future, only $18 \%$ of respondents said they had. This again varied, with $43 \%$ of respondents with asthma saying they had received this advice compared with $5 \%$ with sarcoidosis, $4 \%$ with CF, and none with LAM.

\section{Attitudes and beliefs around lung disease and pregnancy}

During pregnancy, respondents with CF and LAM were more concerned about the impact of their conditions than respondents with asthma and sarcoidosis. For example, respondents with CF and LAM were most likely to consider the impact of pregnancy on their body and lungs to be very or extremely important, while those with asthma and sarcoidosis were most likely to say that it was not very or not at all important $\left(\chi^{2}(1, \mathrm{n}=106)=7.6428, \mathrm{p}=0.0057\right)$. 
During pregnancy, respondents were more concerned about the potential impact on their baby of stopping or changing treatments than on their own health: for example, $90 \%$ of respondents with CF and $65 \%$ with asthma said they considered the safety of changing or stopping their lung treatments when pregnant to be very or extremely important for the baby, but this fell to $77 \%$ and $47 \%$, respectively, when considering their own health.

Reported attitudes and beliefs before pregnancy usually indicated lower concern. For example, before pregnancy, 24\% of those with asthma, 55\% with CF and 54\% with LAM rated the possibility of increased risks during pregnancy because of their lung condition as extremely or very important. This rose to $44 \%$, $78 \%$ and $82 \%$, respectively, when considering this possibility during pregnancy.

Of respondents with CF, 54\% reported not having had a pregnancy, compared to $40 \%$ of respondents with asthma; $63 \%$ of respondents with CF said that their lung condition had been the biggest influence in their decision about whether to have children, compared to $14 \%$ of those with asthma.

\section{Open-ended data analysis}

Table 4 illustrates the four main themes that arose from the analysis of free text responses.

Pregnancy and childbirth is one thing, but the concern about caring for a child can be greater

For many respondents it was not pregnancy or childbirth that were the main concerns, but their ability to deal with the demands of parenthood. Many with CF said they had decided not to have children because

\section{TABLE 4 Main themes from open-ended data analysis with illustrative quotes}

Theme

Pregnancy and childbirth is one thing, but the concern about caring for a child can be greater

Fear of a child getting the lung condition
Receiving no or conflicting advice and understanding risk "How to deal with GPs who don't know enough about managing asthma, one even

\section{Illustrative quotes}

"My whole life has changed with this disease, even without a child. That's why you think twice if you can look after yourself and a child." (Spanish sarcoidosis respondent)

"It is still an issue whether a second or third child will come, because being a mother with a lung disease demands a lot and you sometimes don't feel up to the task." (German sarcoidosis respondent)

"I am afraid that I will not be able to have children and that even if I do, I may die early and leave them without a mother" (Greek CF respondent)

"I see pregnancy as very difficult for women with severe-grade cystic fibrosis and I am always tortured by it since for most people, the dream is to have a family. I especially feel bad for my partner since he loves children and I do not know if we can be parents together in the future.” (Spanish CF respondent)

"I wasn't properly informed about the risks. I just knew about a not entirely clear possibility of genetic disposition.” (German sarcoidosis respondent)

"The prospects of passing my asthma to any future children frightens me and I would consider genetic testing." (UK asthma respondent)

"I have thought about the risk of my child getting my condition, and thus consulted professionals for a genetic analysis of my husband to make sure we could have children without the condition." (Danish CF respondent) suggested I moved house as there was nothing more to be done for me." (UK asthma respondent)

"Unfortunately no one could really provide information. The answer was always ... it gets better, stays the same, gets worse... not really insightful.” (German sarcoidosis respondent)

"We hoped that after giving birth I would return to my normal state, but that was not the case...my general condition is not at all as before my pregnancy. I must say that we weren't really prepared for this, pregnancy was the unknown but we never thought that my general condition would be what it is today so long after." (Belgian CF respondent)

Worries about medication

"I'm not sure ... whether my medication could harm my unborn child, especially in the event of an emergency." (German asthma respondent)

"Information about conceiving and also breastfeeding whilst taking Rapamycin. I believe only around three women worldwide have been pregnant whilst taking this medication and no animal testing or lab testing has taken place in this area." (UK LAM respondent)

"After birth when my chest was sore from using gas and air ... it was dismissed ... I took it upon myself to increase my preventer medication with no advice given as to how this may or may not affect my milk.” (UK asthma respondent) 
of fears about not being able to parent due to their condition, and of leaving their child without a mother. These fears could often leave respondents feeling conflicted. Others chose to limit the number of children they had or to become pregnant at a younger age.

\section{Fear of a child getting the lung condition}

Respondents with sarcoidosis felt uncertain about the risks of their child inheriting the illness, while those with CF were aware of the testing they could have. Respondents with asthma worried about their children inheriting their condition, even though there is no genetic test for this.

\section{Receiving no or conflicting advice and understanding risk}

Many respondents with asthma reported receiving poor or no advice from primary care providers and would have liked input from a respiratory physician or specialist. Respondents with sarcoidosis received conflicting advice and were unclear as to the impact of their condition. Some reported delaying pregnancy as they were unsure of the consequences for them and their potential child.

Some respondents with LAM felt there was a lack of information on the potential effects of their condition and treatment, while others reported being advised not to have children, or choosing not to have children due to their condition. Some wondered whether they would regret this decision in the future.

Respondents with CF often felt informed about the risks and options, such as fertility treatment and surrogacy, even if they were not always available or acceptable to them. Many who chose to try to get pregnant decided to do this at a younger age. Some reported that their condition was not impacted by pregnancy, with a few saying that their lung health had even improved. However, others with CF reported a decline in their lung function postnatally, with some being unprepared for this. Some with LAM also reported a similar decline, but most reported being aware this could happen, and some gave this as a reason for not becoming pregnant.

Some respondents with asthma reported not considering that their lung condition might have an impact on pregnancy and childbirth, and were then surprised when they had issues with their asthma during pregnancy.

\section{Worries about medication}

Respondents were worried and not always clear about the impact of their medication on the fetus. Worries about how medication might impact on breastfeeding a baby were also expressed, and many women reported feeling unsupported.

Those with CF were particularly concerned about an expected decline in their own health during pregnancy due to changes in treatment, for example needing to stop certain medications because they are unsafe for use during pregnancy.

\section{Information and support needs}

Respondents wanted psychological support; clearer information from healthcare professionals; more information on the impact of their disease on pregnancy, the developing fetus, childbirth and breastfeeding; better integration between maternity and respiratory services and better access to respiratory specialists.

Women with CF and LAM - conditions that could be more seriously affected by pregnancy and childbirth particularly wanted information about peers, for example the health status of those who had decided to get pregnant with their lung condition, and how they had coped with pregnancy. Many pointed out that owing to advances in treatment, women with CF were now often able to achieve successful pregnancies, but as this was a relatively new occurrence there was a shortage of such testimonials.

\section{Discussion}

Our data show differences in the perceived impact of certain lung conditions on pregnancy and family planning decisions. While it is perhaps not surprising that for those with conditions in which pregnancy presents higher risks, such as CF and LAM, decisions around all aspects of family planning are closely linked to their lung health and, consistent with previous research, they express more concern about the impact of pregnancy on their health [28, 30, 33]; those with lower-risk conditions, such as asthma and sarcoidosis, do have concerns about the effect of their condition on pregnancy, labour and birth and are dissatisfied with information received. People with asthma are more likely to receive care in a primary care setting, with less access to respiratory specialists, which could account for this difference. Previous 
research has also indicated dissatisfaction with information received during pregnancy for women with asthma, who felt a lack of concern for their lung condition from primary care professionals [28, 30, 37].

These results suggest that there may be a need for specialist advice and support for all women with lung conditions during pregnancy, not just those whose condition presents a higher risk. Many in our study commented on a lack of communication between respiratory and reproductive healthcare professionals, and this has been identified in other studies [27, 37].

Women weigh up a range of complex factors in their decision to have children. Some feel conflicted and worry that they might later regret their choice. Other research has also shown that women with CF aim to balance their own health needs with the needs of their children, and this can lead to feelings of guilt, and lower adherence to treatment $[4,29]$. Some in our study had fewer children or chose pregnancy at a younger age than they might have done if they had not had CF; this is in contrast to other research which found that for most women with CF, the benefits of parenthood outweighed the risks [29].

As identified in previous research [34], respondents with LAM sometimes chose not to get pregnant because of the perceived impact of the condition on their own health. For women with sarcoidosis, the decision to try to have children was filled with uncertainty and perceived mixed messages from health professionals. For asthma respondents, their disease often played little to no part in their decision to have children, but some reported surprise that their asthma worsened during or after pregnancy; this has been found in previous research [27, 36]. This again suggests the need for more specialist support and evidence-based advice for all women with lung conditions.

Women wanted holistic information and support before, during and after their pregnancy, and health professionals should consider signposting or referring women to other sources of support and advice, such as psychological support, support groups and, where appropriate, genetic testing.

Before and during pregnancy, respondents were more likely to believe that the safety of changing or stopping their treatment was more important for the health of the baby than for themselves; this aligns with previous research findings that asthmatic women may cease treatment because of concerns about the effect on the child [28] and suggests that women may be prioritising the baby's health over their own. Many had not been informed of the potentially protective effect of breastfeeding on the infant and most had not received information about breastfeeding with a lung condition.

Lack of information was a theme in several areas, along with dissatisfaction with information received. Over a quarter of women rated the information they received from a primary care professional before pregnancy as poor or very poor, suggesting a training need for these professionals or more referrals to specialist care. While there was a higher level of satisfaction with information received from respiratory professionals, around a sixth of women still rated it as poor or very poor. Our results suggest that planning for pregnancy with a lung condition needs to start early. Professionals should be aware that, in the absence of clear information and open discussions, women with lung conditions may make uninformed and potentially risky decisions around family planning and medications. Women should be better supported to make informed decisions, with space in routine appointments to discuss their desire to have a family. This should be followed by consistent support during and following pregnancy to help respiratory patients understand the risks and benefits of different approaches and provide access to evidence-based information and specialist services.

\section{Strengths}

This survey was designed in partnership with patients and patient representative organisations. It received many responses across countries in nine languages. The exploratory findings provide valuable insight into the experiences of people with a lung condition during family planning and pregnancy and highlight areas for future research. In particular the survey provides novel data on the experiences of women with sarcoidosis, an area not previously explored.

\section{Limitations}

Gathering patient perspectives presents methodological challenges. The method used meant that we cannot calculate the survey's reach or response rate. We received fewer responses from women with sarcoidosis and LAM compared with asthma and CF, so care must be taken when comparing these populations and extrapolating the data to a wider group. 
TABLE 5 Recommendations for practice

Initiate discussions around family planning with respiratory patients during routine appointments Provide clear, evidence-based information about fertility, safety of changing or stopping treatment for the patient and the fetus, impact of pregnancy and labour on current and future health, genetic predisposition, and lifestyle factors

Signpost to psychological support and genetic testing where appropriate

Provide information on the safety of respiratory medications during breastfeeding

Ensure patients receive holistic care from both respiratory and pregnancy health professionals and that pregnancy health professionals can refer patients with queries to relevant respiratory professionals and evidence-based information

The self-selection approach could lead to bias. Individuals who complete a survey tend to have had either a very good or very bad experience and want to communicate this, which could result in fewer responses from the middle ground [38]. Using patient organisations to help disseminate the survey could also lead to a higher proportion of responses from patients who are knowledgeable and highly involved in their healthcare.

\section{Conclusion and recommendations}

Lung disease is often a major consideration for women when making decisions on family planning, pregnancy and birth. Although this is especially true for those with higher-risk conditions, having a lung disease plays a part for most patients. Women want more information about the effect of their condition on their fertility, pregnancy, child and ability to parent, and many are dissatisfied with the information they receive. They also want information on the possible impact of their pregnancy on their future health. Psychological support is often lacking, and women report receiving conflicting information. More research is needed to understand the safety of respiratory treatments during pregnancy and breastfeeding, and this should be shared in clear, accessible formats to facilitate informed decision-making. Services such as the Drugs in Breastmilk Information Service [39], the EU-funded 'ConcePTION' initiative [40] and forthcoming European Medicines Agency strategy on medicine safety during pregnancy and breastfeeding [41] may help to fill the information void. Patient organisations should also consider providing tailored information on family planning and pregnancy, such as the guide from LAM Action on LAM and pregnancy [5].

The ERS/TSANZ Task Force Statement on the management of reproduction and pregnancy in women with airways diseases [3] may help to address the evidence gap and allow health professionals to provide more tailored and up-to-date information for patients, including on medicines safety before and during pregnancy and breastfeeding. Healthcare providers within respiratory, primary and reproductive care should be having conversations with affected women before, during and after pregnancy, and training should be provided to healthcare staff to equip them with the information they need. Table 5 summarises areas for health professionals to consider when providing respiratory and pregnancy-related care, according to the survey data.

Further research could examine the impact on patients of receiving such information, for example whether it leads to greater satisfaction with care during pregnancy and patients feeling more informed when making decisions.

Acknowledgements: The authors would like to thank the following patient and patient group representatives for their input into the design of the survey: Marta Almagro, Annette Posthumus, Betty Frankemölle, Kenneth Hilliyard, Katie Gathercole (European Lung Foundation, Sheffield, UK), Hilde de Keyser (Cystic Fibrosis Europe, Brussels, Belgium), Jasmine Parkinson (Asthma UK, London, UK) and Jill Pateman (LAM Action, Newark, UK). We would also like to thank the members of the European Lung Foundation Patient Organisation Network for their help in disseminating the survey.

Provenance: Submitted article, peer reviewed.

This study has supplementary material available from openres.ersjournals.com

Conflict of interest: C. Williams is an employee of the European Lung Foundation. B. Johnson was an employee of the European Lung Foundation at the time of the study. P.G. Gibson reports support for the present manuscript from the National Health and Medical Research Council; and grants of contracts from AstraZeneca and 
GlaxoSmithKline, payment or honoraria for lectures, presentations, speakers' bureaus, manuscript writing or educational events for AstraZeneca, GlaxoSmithKline and Novartis, and participation on data safety monitoring or advisory boards for Chiesi and Sanofi, outside the submitted work. V. Backer has nothing to disclose. G. Hollis has nothing to disclose. C. Coleman is an employee of the European Lung Foundation.

\section{References}

1 Bláfoss J, Hansen AV, Sara SML, et al. Female asthma and atopy - impact on fertility: a systematic review. J Asthma Allergy 2019; 12: 205-211.

2 Ali Z, Hansen AV, Ulrik CS. Exacerbations of asthma during pregnancy: impact on pregnancy complications and outcome. J Obstet Gynaecol 2016; 36: 455-461.

3 Middleton PG, Gade EJ, Aguilera C, et al. ERS/TSANZ task force statement on the management of reproduction and pregnancy in women with airways diseases. Eur Respir J 2020; 55: 1901208.

4 Jacob A, Journiac J, Fischer L, et al. How do cystic fibrosis patients experience parenthood? A systematic review. J Health Psychol 2021; 26: 60-81.

5 LAM Action. Living with LAM: LAM and Pregnancy. http://lamaction.org/wp-content/uploads/2021/03/Living with-LAM-LAM-and-Pregnancy.pdf. Date last accessed: 24 November 2021. Date last updated: February 2021.

6 Taveira-Dasilva AM, Johnson SR, Julien-Williams P, et al. Pregnancy in lymphangioleiomyomatosis: clinical and lung function outcomes in two national cohorts. Thorax 2020; 75: 904-907.

7 Sarcoidosis UK. Sarcoidosis and Children. www.sarcoidosisuk.org/information-hub/sarcoidosis-children/. Date last accessed: 24 November 2021.

8 Vahid B, Mushlin N, Weibel S. Sarcoidosis in pregnancy and postpartum period. Curr Respir Med Rev 2007; 3: 79-83.

9 Hadid V, Patenaude V, Oddy L, et al. Sarcoidosis and pregnancy: obstetrical and neonatal outcomes in a population-based cohort of 7 million births. J Perinat Med 2015; 43: 201-207.

10 Global, regional, and national incidence, prevalence, and years lived with disability for 328 diseases and injuries for 195 countries, 1990-2016: a systematic analysis for the Global Burden of Disease Study 2016. Lancet 2017; 390: 1211-1259.

11 Asthma and Allergy Foundation of America. Asthma Facts and Figures. www.aafa.org/asthma-facts/. Date last accessed: 24 November 2021. Date last updated: April 2021.

12 European Lung Foundation. Adult Asthma. www.europeanlung.org/en/information-hub/lung-conditions/ adult-asthma. Date last accessed: 24 November 2021. Date last updated: 26 July 2021.

13 Caminati M, Morais-Almeida M, Bleecker E, et al. Biologics and global burden of asthma: a worldwide portrait and a call for action. World Allergy Organ 2021; 14: 100502.

14 McClenaghan A, Cosgriff A, Brownlee K, et al. The global impact of SARS-CoV-2 in 181 people with cystic fibrosis. J Cyst Fibros 2020; 19: 868-871.

15 Cystic Fibrosis Foundation. About Cystic Fibrosis. www.cff.org/What-is-CF/About-Cystic-Fibrosis/. Date last accessed: 24 November 2021.

16 Cystic Fibrosis Foundation. An Introduction to Cystic Fibrosis for Patients and their Families. www.cff.org/ Intro-to-CF.pdf. Date last accessed: April 28 2021. Date last updated: 2013.

17 Cystic Fibrosis Worldwide. What is Cystic Fibrosis? www.cfww.org/what-is-cystic-fibrosis. Date last accessed: 24 November 2021.

18 European Lung Foundation. Lymphangioleiomyomatosis (LAM). https://europeanlung.org/en/information-hub/ factsheets/lam/. Date last accessed: 24 November 2021. Date last updated: 10 June 2021.

19 LAM Action. What is LAM? http://lamaction.org/about-lam/what-is-lam/. Date last accessed: April 282021.

20 The LAM Foundation. What is LAM? www.thelamfoundation.org/Newly-Diagnosed/Learning-About-Lam/ About-LAM. Date last accessed: 24 November 2021.

21 Oprescu N, McCormack FX, Byrnes S, et al. Clinical predictors of mortality and cause of death in lymphangioleiomyomatosis: a population-based registry. Lung 2013; 191: 35-42.

22 European Lung Foundation. Sarcoidosis. https://europeanlung.org/en/information-hub/factsheets/sarcoidosis/ Date last accessed: 24 November 2021. Date last updated: 30 June 2021.

23 British Lung Foundation. Sarcoidosis Statistics. https://statistics.blf.org.uk/sarcoidosis. Date last accessed: 24 November 2021.

24 Foundation for Sarcoidosis Research. Diagnosis. www.stopsarcoidosis.org/what-is-sarcoidosis/diagnosis/. Date last accessed: 24 November 2021.

25 Foundation for Sarcoidosis Research. Sarcoidosis FAQs. www.stopsarcoidosis.org/living-with-sarcoidosis/faqs/. Date last accessed: 24 November 2021.

26 Simcox AM, Duff AJ, Morton AM, et al. Decision making about reproduction and pregnancy by women with cystic fibrosis. Br J Hosp Med (Lond) 2009; 70: 639-643.

27 Cammidge SL, Duff AJA, Latchford GJ, et al. When women with cystic fibrosis become mothers: psychosocial impact and adjustments. Pulm Med 2016; 9458980: 1-11. 
Lim AS, Stewart K, Abramson MJ, et al. Asthma during pregnancy: the experiences, concerns and views of pregnant women with asthma. J Asthma 2012; 49: 474-479.

Hailey CE, Tan JW, Dellon EP, et al. Pursuing parenthood with cystic fibrosis: reproductive health and parenting concerns in individuals with cystic fibrosis. Pediatr Pulmonol 2019; 54: 1225-1233.

Chamberlain C, Williamson GR, Knight B, et al. Investigating women's experiences of asthma care in pregnancy: a qualitative study. Open Nurs J 2014; 11: 56-63.

Belkin A, Albright K, Fier K, et al. 'Getting stuck with LAM': patients perspectives on living with lymphangioleiomyomatosis. Health Qual Life Outcomes 2014; 12: 79.

32 Fair A, Griffiths K, Osman LM. Attitudes to fertility issues among adults with cystic fibrosis in Scotland. Thorax 2000; 55: 672-677.

Kazmerski TM, Gmelin T, Slocum B, et al. Attitudes and decision making related to pregnancy among young women with cystic fibrosis. Matern Child Health J 2017; 21: 818-824.

Cohen MM, Freyer AM, Johnson SR. Pregnancy experiences among women with lymphangioleiomyomatosis. Respir Med 2009; 103: 766-772.

Braun V, Clarke V. Using thematic analysis in psychology. Qual Res Psychol 2006; 3: 77-101.

Braun V, Clarke V. Reflecting on reflexive thematic analysis. Qual Res Sport Exerc Health 2019; 11: 589-597.

Williamson GR, O'Connor A, Kayleigh EJ. Women's experiences of personalised support for asthma care during pregnancy: a systematic review of the literature. BMC Pregnancy Childbirth 2017; 17: 69.

Ahmed F, Burt J, Roland M. Measuring patient experience: concepts and methods. Patient 2014; 7: 235-241.

The Breastfeeding Network. Drugs in Breastmilk - Is it Safe? www.breastfeedingnetwork.org.uk/ detailed-information/drugs-in-breastmilk/. Date last accessed: 24 November 2021. Date last updated: April 2019.

Conception. www.imi-conception.eu/. Date last accessed: 24 November 2021.

European Medicines Agency. Workshop: Safe Use of Medicines During Pregnancy and Breastfeeding. www. ema.europa.eu/en/news/workshop-safe-use-medicines-during-pregnancy-breastfeeding. Date last accessed: 24 November 2021. Date last updated: 8 July 2020. 